Editorial

Changing the world

Peter McGill, Tizard Centre

\title{
Change of editor
}

As the new Editor of the Review I would like to begin with a tribute to Jim Mansell who established TLDR in 1996 and has been Editor for the majority of the years since. Jim's vision, in seeing the need for and value of such a journal, was prescient. It has always been the case that the impact of much academic research or of new service developments remains limited as we all burrow away in our separate bunkers. TLDR provides a way in which researchers and practitioners can communicate. It doesn't solve the problem but does provide an important avenue for dissemination and exchange of ideas. The need for such avenues is increasingly recognised. Plans for the next assessment of the quality of University research have proved controversial, in part because of proposals to try to evaluate the "impact" that research has had. TLDR is ultimately about impact - attempting to find ways in which new ideas can be communicated, discussed, evaluated and used quickly and concisely. We are lucky to have it.

The current issue

So what of the impact of the articles in the current issue? Liam Newton and colleagues complete their account of the SHEALD project, a community-based sex offender assessment and treatment service, with an accompanying commentary by Angela Olsen and Michael Ravey. These articles prove neatly complementary, the former drawing attention to the technical sophistication of the approaches that may be needed, the latter to the broader social care context within which the approaches are carried out. We know all too well that technical sophistication, however necessary, is not always sufficient to bring about better lives for people with learning disabilities. The desired impact here is that health and social care practitioners can work together, respecting each other's skills and ways of working.

Roger Stancliffe and colleagues also describe a relatively technical piece of work suggesting that active support training may enhance the value of having additional staff. Active support is a very good example of the impact agenda. Although its basis was first developed in Andover in the 1970s its broader impact on the lives of people with learning disabilties was, until the late 1990s, limited mainly to demonstration projects carried out in conjunction with academic centres. The pioneers of active support are, however, to be commended for the extensive work done to achieve broader take up. This included the development of training materials (e.g., Jones, et al., 1997; Mansell, BeadleBrown, Ashman, \& Ockenden, 2004), research specifically focused on training and dissemination (e.g., Bradshaw, et al., 2004; Jones, et al., 1999) and the use of journals such as TLDR (e.g., Mansell, 1998; Sanderson, 2002) to spread the message. There is no room for complacency but the widespread take up of active support in the UK, Australia and elsewhere suggests it is a success story for the impact agenda. 
Claire Wilson's article considers the spiritual needs of people with learning disabilities. When we consider the importance that spirituality (with or without organised religion) plays in the lives of so many people, its relative neglect in the lives of people with learning disabilities is notable. I am sure Claire hopes that her article will result in these issues being given more attention by her colleagues. In the current economic context that might seem unlikely but Claire (and all our other authors) should not despair - "Never doubt that a small group of thoughtful, committed citizens can change the world. Indeed it is the only thing that ever has" (Margaret Mead).

Farewell to old friends

Sad news has come in over the last few months of the deaths of two pioneers in the learning disability world, both of whose work has certainly made an impact.

Wolf Wolfensberger is best known for his development of the concepts of normalisation (the North American version) and social role valorisation. He was a frequent visitor to the UK in the 1970s and 80 s and had considerable, world-wide influence on the development of community-based services. Often a controversial figure, his work can be seen as having led to modern emphases on rights and personalisation. He was also one of the first people to note the risks of abuse of people with learning disabilities and to focus on the importance of advocacy and protective services. A good introduction to his work can be found in David Race's book (Race, 2003).

Chris Kiernan was one of the foremost UK researchers in learning disability from the 1970 s on. His work on communication (especially on alternatives to speech) and challenging behaviour was especially influential. Having worked at the Thomas Coram Research Unit in London he became Professor and Director of the Hester Adrian Research Centre (HARC) at the University of Manchester in the 1980s. HARC (originally set up by Peter Mittler) was, at the time, the pre-eminent centre of research in learning disability in the UK. With Department of Health funding, Chris, Eric Emerson and others continued this tradition well into the 90s with major and influential studies, for example, on the epidemiology of challenging behaviour. Chris always had a concern for the impact of research. I still have one of his books ("Starting Off", published in 1980) on my shelves - one of the first attempts to provide information from research in a manner accessible to teachers, families and others.

\section{References}

Bradshaw J, McGill P, Stretton R, Kelly-Pike A, Moore J, Macdonald S, et al. (2004) Implementation and evaluation of active support. Journal of Applied Research in Intellectual Disabilities 17 139-148.

Jones E, Perry J, Lowe K, Felce D, Toogood S, Dunstan F, et al. (1999) Opportunity and the promotion of activity among adults with severe intellectual disability living in community residences: the impact of training staff in active support. Journal of Intellectual Disability Research 43 (3) 164-178.

Jones E, Perry J, Lowe K, Felce D, Toogood S, Dunstan F, et al. (1997) Active Support Trainers Manual. Cardiff: Welsh Centre for Learning Disabilities.

Mansell J (1998) Active support. Tizard Learning Disability Review 3 (2) 4-6. 
Mansell J, Beadle-Brown J, Ashman B, \& Ockenden J (2004) Person-Centred Active Support. Brighton: Pavilion Publishing.

Race DG (Ed.) (2003) Leadership and Change in Human Services: Selected Readings from Wolf Wolfensberger. London: Routledge.

Sanderson H (2002) Active support and person-centred planning: Strange bedfellows or ideal partners? Tizard Learning Disability Review 7 (1) 31-38. 